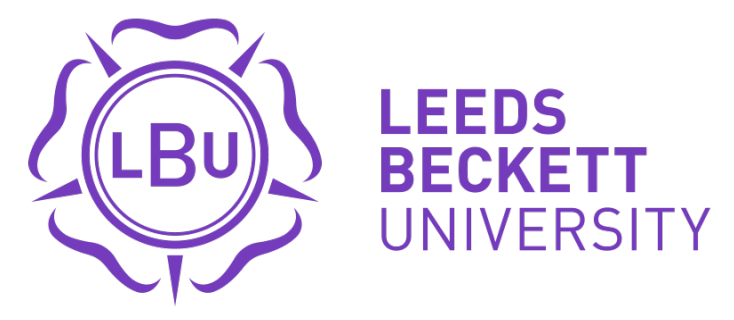

Citation:

Chang, V and Wills, G and De Roure, D (2010) A review of cloud business models and sustainability. In: Proceedings - 2010 IEEE 3rd International Conference on Cloud Computing, CLOUD 2010. UNSPECIFIED, 43 - 50. ISBN 9780769541303 DOI: https://doi.org/10.1109/CLOUD.2010.69

Link to Leeds Beckett Repository record:

https://eprints.leedsbeckett.ac.uk/id/eprint/627/

Document Version:

Book Section (Accepted Version)

The aim of the Leeds Beckett Repository is to provide open access to our research, as required by funder policies and permitted by publishers and copyright law.

The Leeds Beckett repository holds a wide range of publications, each of which has been checked for copyright and the relevant embargo period has been applied by the Research Services team.

We operate on a standard take-down policy. If you are the author or publisher of an output and you would like it removed from the repository, please contact us and we will investigate on a case-by-case basis.

Each thesis in the repository has been cleared where necessary by the author for third party copyright. If you would like a thesis to be removed from the repository or believe there is an issue with copyright, please contact us on openaccess@leedsbeckett.ac.uk and we will investigate on a case-by-case basis. 


\title{
A Review of Cloud Business Models and Sustainability
}

\author{
Victor Chang, Gary Wills, David De Roure \\ School of Electronics and Computer Science, University of Southampton, \\ Southampton SO17 1BJ. United Kingdom \\ \{vic1e09,gbw, dder\}@ecs.soton.ac.uk
}

Keywords: Cloud Business Models; Cloud Cube Model; Hexagon Model; Sun Tzu's Art of War; Sustainability; Capital Asset Pricing Model; Modern Portfolio Theory and 3D Visualisation.

\begin{abstract}
This paper reviews current cloud computing business models and presents proposals on how organisations can achieve sustainability by adopting appropriate models. Using the Jericho Forum's Cloud Cube Model (CCM), we classify cloud computing business models into eight types: (1) Service Provider and Service Orientation; (2) Support and Services Contracts; (3) In-House Private Clouds; (4) All-In-One Enterprise Cloud; (5) One-Stop Resources and Services; (6) Government Funding; (7) Venture Capitals; and (8) Entertainment and Social Networking. We newly propose the Hexagon Model that includes six key elements for sustainability based on Sun Tzu's Art of War and literature review, and the sixth factor is rated based on case studies and peer reviews. Areas occupied in the Hexagon can represent strengths and weaknesses of a cloud business, and several cases are presented with rationale explained. Apart from the qualitative approach, the quantitative approach we use is the Capital Asset Pricing Model and Modern Portfolio Theory, both of which aim computing organisational sustainability and predict how well an organisation can perform. The OMII-UK data is used to demonstrate sustainability and study the impact on cloud businesses, and is presented by statistical computation, 3D visualisation and the Hexagon Model. We believe that adopting an appropriate cloud computing business model will help organisations investing in this technology to stand firm at all times.
\end{abstract}

\section{Introduction}

Cloud Computing aims to provide scalable and inexpensive on-demand computing infrastructures with good quality of service (QoS) levels. More specifically, this involves a set of network-enabled services that can be accessed in a simple and pervasive way [22]. It also provides added value for organisations; saving costs in operations, resources and staff - as well as new business opportunities for service-oriented models [3, 4, 11, 22]. In addition, it is likely that cloud computing focusing on operational savings and green technology will be at the centre of attention. To avoid repeats of Internet bubbles and to maintain business operations, achieving long-term sustainability is an important success factor for organisations [5]. In this paper we review current cloud computing business models, and provide recommendations on how organisations can achieve sustainability by adopting appropriate models.

Extensive work has been done on investigating business models empowered by Cloud technologies [19]. Despite leading IT vendors such as Amazon, Microsoft, Google, IBM and Salesforce taking the lead, the amount of investment and spending is still more than the profits received from these investments. This illustrates the importance of classifying the right business strategies and models for long-term sustainability. There are two business models presented in this paper, and the first is Cloud Cube Model (CCM) from The Jericho Forum (JF), which we have added our classification and categorised into eight business models. The second is the Hexagon model, which is we propose based on a review of business literature [1,12,23] and essence from Sun Tzu's Art of War, which is rated as the "Bible of War" in the East, and lessons learned have been studied and used extensively in the business strategies. The Hexagon model identifies six key elements for business sustainability and presents how a business or a cloud project performs in these six elements. This enables the strengths and weaknesses of a cloud business or project to be presented in visual and easy to understand ways. Apart from the qualitative approach, the quantitative approach we use is the Capital Asset Pricing Model (CAPM) and Modern Portfolio Theory (MPT), both of which aim computing organisational sustainability and predicts how well an organisation can perform. The case study of OMII-UK is presented.

\section{The Cloud Cube Model and Our Updated Definitions}

The Cloud Cube Model (CCM) proposed by the Jericho Forum (JF) is used to enable secure collaboration in the appropriate cloud formations best suited to the business needs [14]. The JF points out that many cloud service providers claim to be able to deliver solutions, so cloud customers need help in selecting the right formation within CCM suiting their needs.

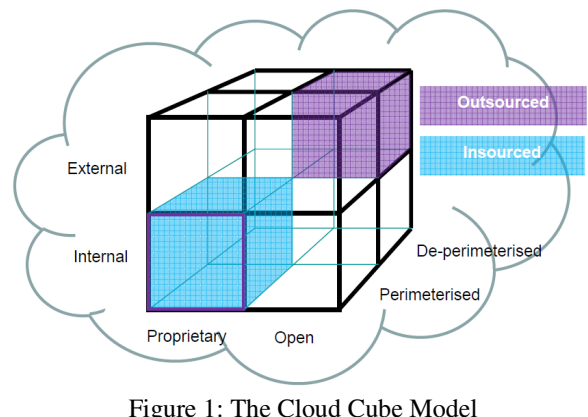

Within CCM, four distinct dimensions are identified. They are (a) External and Internal; (b) Proprietary and 
Open; (c) Perimeterised (Per) and De-Perimeterised (Dp), and (d) In-sourced and Outsourced. Section 2.1 to 2.4 describes how each component fits the business models. The Diagram for CCM is in Figure 1 [14].

\subsection{Internal and External}

This dimension describes the type of business model to go for. Internal means private clouds and External means public clouds.

\subsection{Proprietary and Open}

Proprietary means paid services or contractors. Open stands for open source services or solutions. In the context of cloud computing, sometimes open means a system or platform that allows sharing and free accessing of APIs, and in this respect, Google App Engine can be considered as open.

\subsection{Perimeterised (Per) and De-perimeterised (D-p)}

The original definition refers to $P e r$ and $d-p$ as an architectural mindset - that is, whether traditional IT perimeters such as network and firewall are operating inside (Per) or outside (D-p) the organisation. In our context relevant to cloud computing, perimeterised refers to infrastructure as a service (IaaS) and platform as a service (PaaS), or any services, contracts and supports using infrastructure and platform. De-perimeterised stands for Software as a Service (SaaS), or any services, contracts or supports for software/application, since they are not restricted by hardware boundary [7].

\subsection{Insourced and Outsourced}

Insourced means in-house development of clouds. Outsourced refers to letting contractors or service providers handle all requests, and most of cloud business models fall into this.

\section{Business Model Classifications and How Each Business Model Fits Into the CCM}

In this Section, how each business model fits into the Cloud Cube Model is explained. Strengths and weaknesses for each business model are also presented at the left section. Dark purple is the joint area between outsource and in-house approaches. Based on previously identified use cases, surveys, analysis and reviews of cloud computing business models $[2,5,6,7,14]$, we categorise these models into eight types: (1) Service Provider and Service Orientation; (2) Support and Services Contracts; (3) In-House Private Clouds; (4) AllIn-One Enterprise Cloud; (5) One-Stop Resources and Services; (6) Government funding; (7) Venture capitals and (8) Entertainment and Social Networking. These eight models are summed up as Table 1 below.

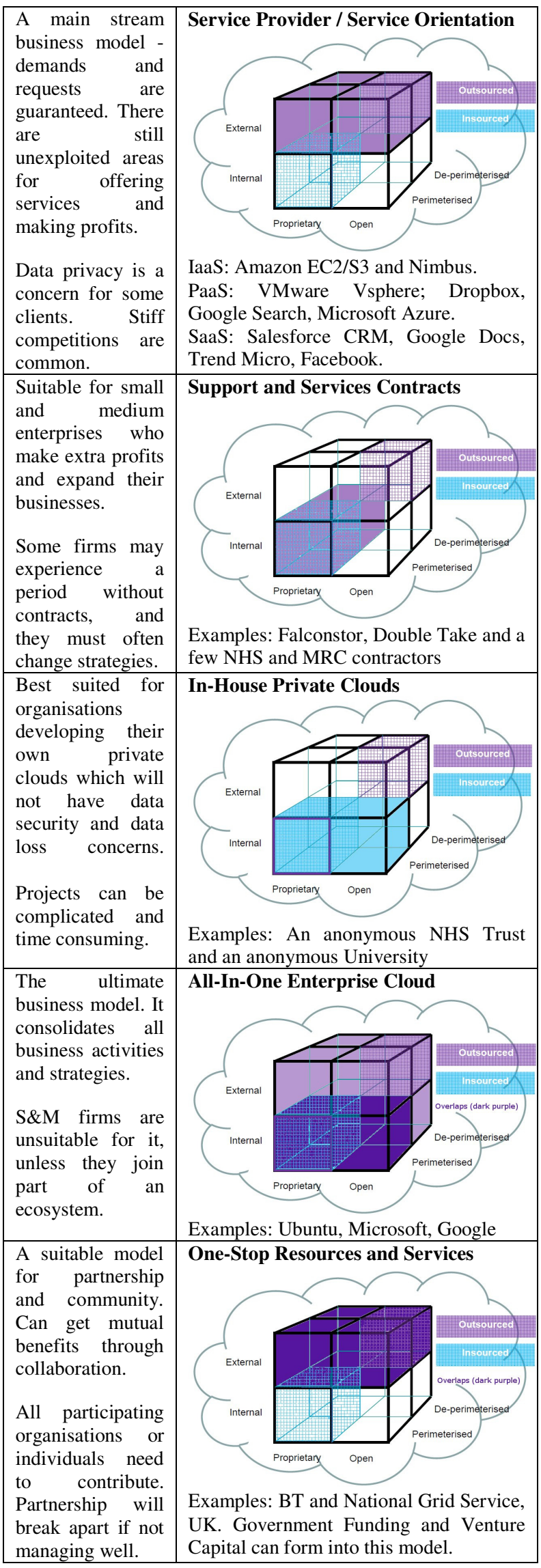




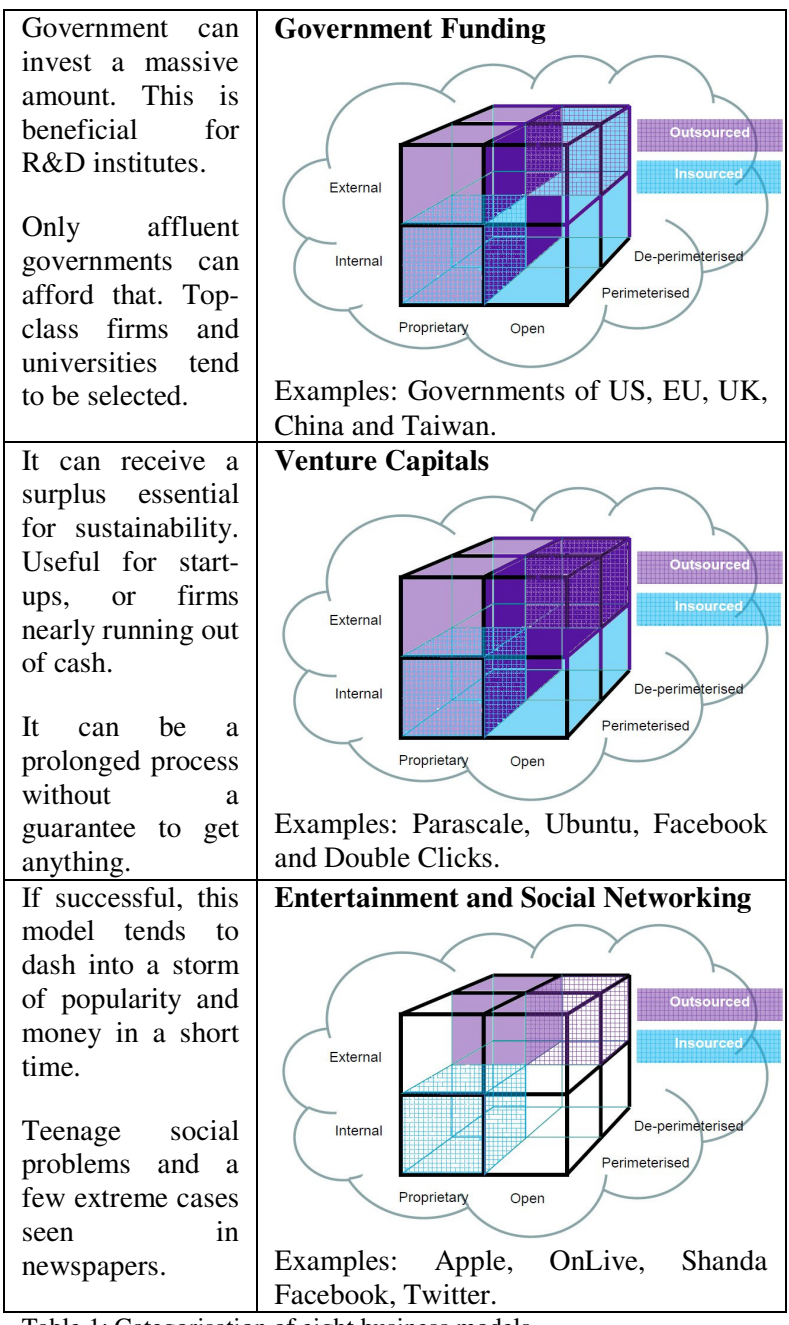

Table 1: Categorisation of eight business models

\section{The Hexagon Model}

Cloud Computing Business Model is a new and emerging area, and a single model cannot fully represent the best business models. In current literature review, there are business models including (a) Cloud Cube Model proposed by Jericho's Forum [14]; (b) pay as you go model demonstrated by major vendors such as Amazon EC2 and S3; (c) seven models proposed by Chou [9]; (d) Cloud OSS Business Model 3.0 presented by Lawson [16]; (e) waterfall models proposed by Jeffery, Schubert and Neidecker-Lutz [13]; and (f) Linear Value Chain and Ecosystem Models proposed by Luhn and Jaekel [20]. Based on various economic and finance reviews [1, 12, 23], there are five elements essential for every successful business. They are high volumes or confidence levels in consumers (customers), investors, popularity (or adoption), market valuation, and innovation. An example is Facebook, which has achieved 400 million users in six years of time, where consumers, investors, popularity, valuation and innovation have reached the peak comparing to competitors and analysts' expectations. Similarly, iPhone storms the market and takes the same route as Facebook. However, there is a missing factor, "get the job done" (GTJD) factor, which implies whether services from a particular service provider can get the client's problems resolved, and whether their solutions are fully relevant as the cloud service, and extents of the impacts offered by this service on clients' organisations. This is essential since some service providers use alternative ways with less relevance to clouds, which are awarded less for the merits of cloud computing. GTJD also needs lowering risks. GTJD is rated based on case studies and peer reviews in the form of surveys and interviews.

\subsection{The idea and origin of the Hexagon Model}

In ancient wars in the East, armies were aligned in formation with the right tactics in battles, and the formation was based on the shape such as hexagon and octagon. This allows armies to simultaneously attack and defend based on their strength, types of armies, tactics, surrounding in the battlefield and enemies' movement. The "arrow" shape in the army implies: it is the severest level of attacks suitable for an infantry. The "triangle" shape implies: it is suitable for cavalry, and is good for speed and attack. The "V" shape implies: it is relevant for archeries, and is good to attack at the back of formation. The "ring" shape implies: it is relevant for any troops, and is excellent for defence. Formations between troops can be evolved at any time to gain more advantages. All these war tactics are available in Art of War by Sun Tzu, who was born in China in around 500 B.C, is highly regarded as the "Saint of War" in the East.

Sun Tzu's Art of War (STAW) has been extensively studied, researched and applied into business strategies, operations, negotiations, sales and leadership. Japan initiated business tactics and operations from the essence of STAW after the Second World War, and since then, STAW was widely studied for business impacts in China, Taiwan, Hong Kong, Korea and South East Asia particularly Singapore. STAW is a topic at some business schools in North America and Europe including publications from Harvard Business Reviews. There are some key contributions from scholars. Firstly, Wee et al. [24] present the seven different strategic processes in relation to STAW. Secondly, Lee and Roberts et al. define thirteen major business strategies and business frameworks to instruct what steps to be taken for different business scenarios [18]. Thirdly, Michaelson has demonstrated how to use STAW to improve execution abilities and to get expected results [21]. Fourthly, Osama El-Kadi is a key speaker based in the UK with his seminars and articles on how STAW can be fully implemented for business strategies, negotiations and leadership [10]. Those publications are good in providing guidelines - instead of simplification, they tend to set additional rules which may be interpreted as complication to original STAW. In our context, we aim to simplify any business implications as an easy to understand approach, which our Hexagon Model fits in well, and can visually present a business or a project's strengths and weaknesses for decision-makers. 


\subsection{The position in the Hexagon Model}

Positions in these six elements reflect their relations to each other. Six elements can be divided into pairs: people (consumers and investors); business (popularity and valuation) and job done with job variance (get the job done, GTJD and innovation). Each pair is opposite to each other in the position of the hexagon. Consumers and popularity are related, so that they are next to each other. Being a popular service, ideally it should have GTJD factor helping client organisation resolving its immediate needs with lowering risks. This in turn assists the service provider gaining trust and reputation, therefore, popularity and GTJD are next to each other. Investors are next to GTJD to ensure the best values of their investment. Valuation is opposite to popularity, and is next to investors. The remaining element, innovation is then next to valuation and consumer respectively. To sum up discussions so far, Figure 2 below is the presentation of our Hexagon Model.

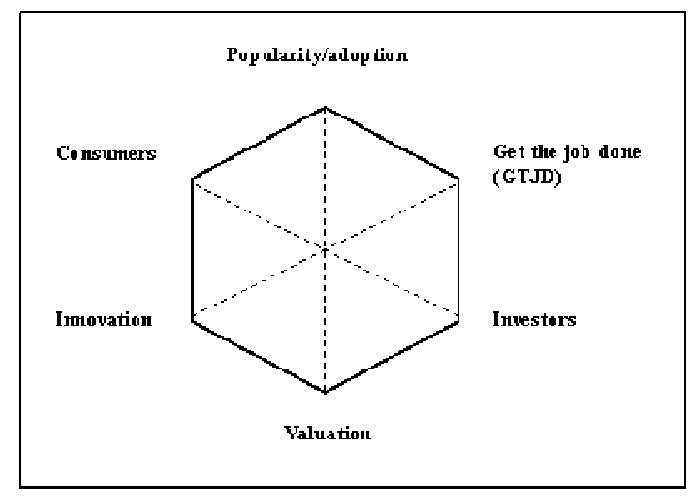

Figure 2: The Hexagon Model

There are three interesting observations related to Hexagon model. Firstly, "get the job done" (GTJD) also includes business at risk, whether their sustainability model is solid enough. Another aspect for risk is whether data on those cloud service may have security implication for client organisations. Thus, a cloud service should not only provide a top quality service, but also need to be aware for non-risk factor. Secondly, the relation between popularity and market valuation may not be proportional to each other. A popular product such as personal computers may not have high valuation. A high valuation military business may not be popular amongst potential clients. However in cloud computing, popularity, valuation and even innovation tend to be proportional to each other. This is evident in cases of Google, Amazon, Facebook and Apple. Being innovative helps them as the leader in the cloud. The difference is also availability of a dedicated, global service provider for either: (1) offering the best quality and user-friendliness amongst competitors (Facebook, Apple) and standing out from the crowd; or (2) offering an unique service as a successful pioneer, and lead by examples that others follow (Amazon EC2/S3; Salesforce, Google). The third observation is that scores for each of the six elements can form an occupied area in the Hexagon model, which can indicate (i) an organisation's or a project's performance and (ii) also its business sustainability in the future.

Measurement for GTJD is based on peer reviews in the form of surveys, quick interviews, phone interviews and publications, and this is particularly useful when peers are also users of those cloud services.

\subsection{Examples demonstrated by the Hexagon Model}

The Hexagon Model is used to demonstrate selected organisations' cloud.

\section{(i) Apple and Facebook}

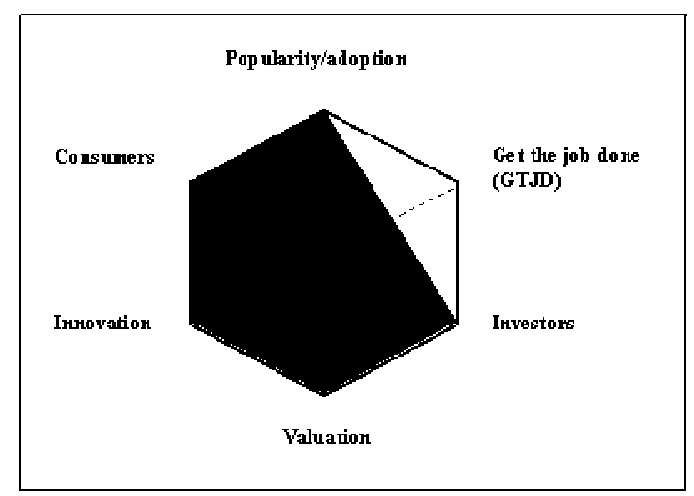

Figure 3: The Hexagon Model for Apple and Facebook

Apple and Facebook are similar that they score exceptionally high for popularity, valuation, consumer, investors and innovation, since all these five factors reflect its key strength and have the ability to score the maximum. However, the nature of their business is classified as entertaining and social networking. Despite the fact that they use cloud, cloud is not their main business orientation, as their services use whatever resources and technologies available to further boost their "wow" factors. Hence, both score lower in GTJD. The Facebook business model was uncertain till they made their first profits in 2009. Whereas for Apple, their mobile services are subject to security concerns and mobile platforms are not ideal for hosting sensitive data. Both firms are expected to improve on GTJD factors. Refer to Figure 3 on page 4 for details.

\section{(ii) Amazon}

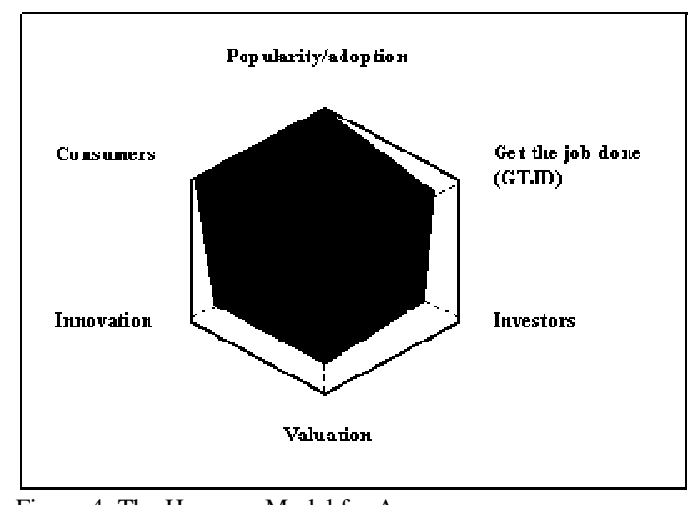

Figure 4: The Hexagon Model for Amazon 
Amazon is a market leader in Infrastructure as a Service (IaaS), and several businesses have followed a similar business model that Amazon has endeavoured. They score exceptionally highly for consumers and popularity. They score high but still have room for improvements for investors, innovation and valuation, which are dependent on their cloud business performance. Peer reviews suggest they are an ideal platform for experiments and backup. There are ongoing hacks to Amazon, thus they score lower for GTJD, where they have potential to improve. See Figure 4 on page 4 .

\section{(iii) Google}

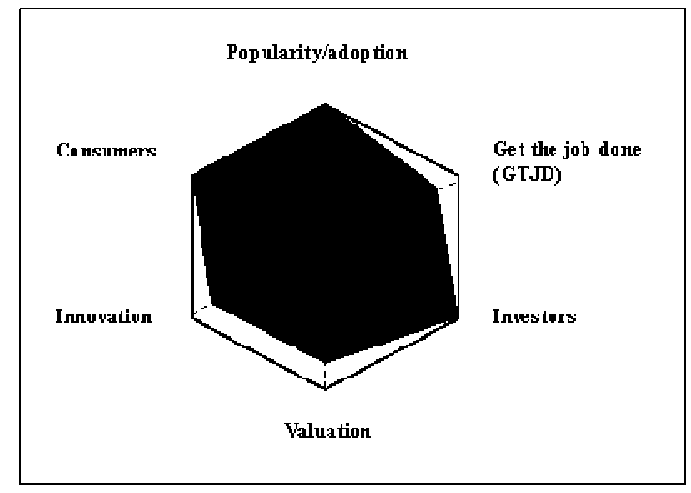

Figure 5: The Hexagon Model for Google

Google performs significantly well for consumer, popularity and investors as reflections of their key strength. Their market valuation is already high before moving to clouds, so they have rooms for improvements. They are innovative to create new products to maintain customers and investors' confidence. Google's Software as a Service is very open and easily accessible with a vast variety, where on a contrast, the weakness is in nonrisk factor, which slightly lowers down GTJD. Refer to Figure 5 for details.

\subsection{Private Cloud}

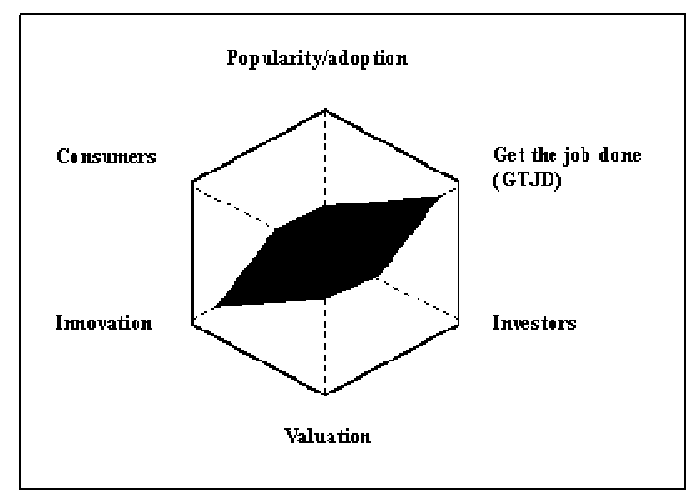

Figure 6: The Hexagon Model for the Private Cloud

A private cloud is a bespoke cloud service usually built or deployed for particular uses within the organisation, thus data and accessibility are only for internal users [6]. In ideal situations, GTJD and innovation should score exceptionally high with lower scores for other fours to match organisational needs. In the private cloud's case, having these two factors high are essential for initial phase of running cloud services, and influence in the occupied areas is not so important at the beginning. However, when a private cloud has been used for some time, consumers, investors, popularity and internal valuation must improve. See Figure 6, a UFO shape.

\section{Capital Asset Pricing Model (CAPM)}

The Capital Asset Pricing Model (CAPM) is a model to calculate investment risks and to determine what expected return on investment is. In the context to cloud computing, it is a quantitative model for sustainability. CAPM was introduced by Jack Treynor (1961, 1962), William Sharpe (1964), John Lintner (1965) and Jan Mossin (1966) respectively, based on Harry Markowitz work on diversification and modern portfolio theory. CAPM divides risk into two groups. The first group is Systematic Risk (also known as beta), the market of which cannot be diversified away, including recessions and interest rates. The second group is unsystematic risk, the risk of which is specific to individual stocks and can be diversified and managed by investors [25]. In CAPM, beta is the only relevant measure of a stock's risk and measures a stock's volatility.

In some interpretations, the security market line (SML) is used to calculate the reward-to-risk ratio. When the expected rate of return for any security is deflated by its beta coefficient, the reward-to-risk ratio for any individual security in the market is equal to the market reward-to-risk ratio, thus:

$$
\left(\boldsymbol{r}-\boldsymbol{r}_{f}\right) / \boldsymbol{\beta}=\boldsymbol{r}_{m}-\boldsymbol{r}_{f}
$$

$\left(\boldsymbol{r}-\boldsymbol{r}_{f}\right)=\boldsymbol{\beta}\left(\boldsymbol{r}_{\boldsymbol{m}}-\boldsymbol{r}_{f}\right)$ and this is known as security market line (SML).

Finally, to best represent CAPM, the formula is given as:

$$
r=r_{f}+\left(\beta \times\left(r_{m}-r_{f}\right)\right)
$$

where $\boldsymbol{r}$ is the expected return of a capital asset $\boldsymbol{r}_{\boldsymbol{f}}$ is the risk free rate

$\boldsymbol{r}_{m}$ is the expected return on the market and

$\boldsymbol{\beta}$ is the beta of the cash flows or security being valued.

The term $r_{m}-r_{f}$ is the market risk premium, which is usually considered implicitly rather than explicitly. Therefore, the term $\beta \times\left(r_{m}-r_{f}\right)$ is the risk premium on the cash flows (or security) being valued.

Here is a CAPM example: If the risk-free rate is $3 \%$, the beta (risk measure) of the firm is 2 and the expected market return over the period is $5 \%$, the stock is expected to return $=(3 \%+2(5 \%-3 \%))=7 \%$.

\subsection{Choices for sustainability modelling - CAPM and Modern Portfolio Theory (MPT)}

Publications on software sustainability focus on qualitative approaches such as business model classifications and its respective methods and strategies 
for reaching sustainability $[5,15]$. There are not many quantitative modelling approaches for this topic. We review mathematical models and selectively study Monte Carlo, ARIMA, Black Scholes and CAPM, the later of which is the most appropriate for quantitative sustainability [8]. There are two main reasons. Firstly, CAPM is suitable in predicting the firms' growth and sustainability if data is defined and given. Secondly, there are more freedom to define the organisational focus, which can be translated as data, and then used for modelling. Some mathematical models are stringent with rules with conditions applied, which is not subjective in CAPM. Furthermore, CAPM is the most effective for linear regression modelling. In our experience with software sustainability, majority of the healthy, active academic projects gets into linear regression formats.

Modern Portfolio Theory (MPT) is a theory of investment aiming to maximise return and minimise risk by carefully selecting different assets. MPT models an asset's return as a normally distributed random variable, define risk as the standard deviation of return, and models a portfolio as a weighted combination of assets [26]. Despite there are criticism about MPT's suitability for finance, the concept of MPT is relevant to software sustainability. This is because firstly, software organisation is less volatile than finance industry where more complex models are required. Secondly, if organisations follow the linear regression, MPT offers an easier way for calculation, in particular tracking organisational growth. Refer to Section 5.4 for details.

\subsection{Using OMII-UK as a case study for CAPM Sustainability modelling}

OMII-UK is an UK-based leader in open source Grid software that their data from the past three years for sustainability have been used in this modelling. Some of these data are provided by OMII-UK, and some are collected by us through active collaboration. CAPM can be modelled by statistical languages, in which SAS is more suitable than other languages since it can compute more in-depth analysis. The following coding algorithm predicts the Risk Premiums of an organisation, OMIIUK versus the Market. The data is carefully calculated, examined and randomised. Three years of data can best represent sustainability from the initial phase to establishment. Up to ten years of data is still preferred for a longer term sustainability. The following part of the code shows variables' definitions and then the plot.

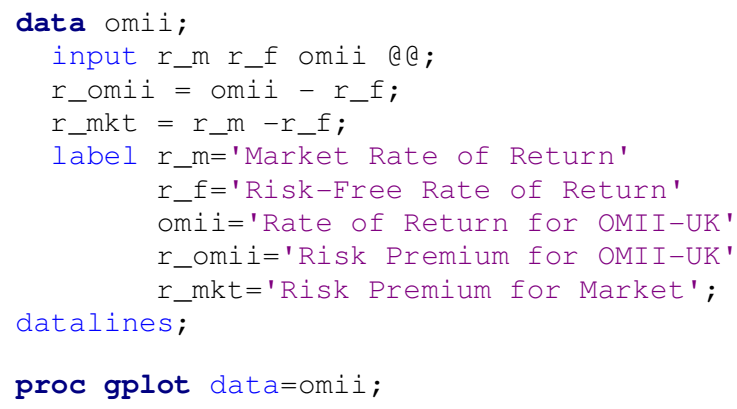

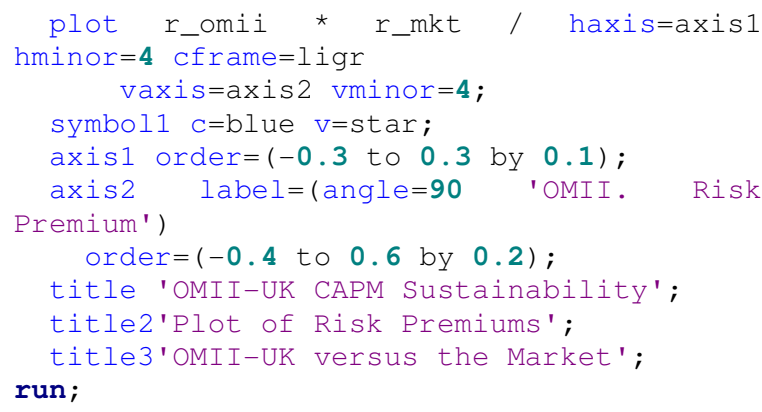

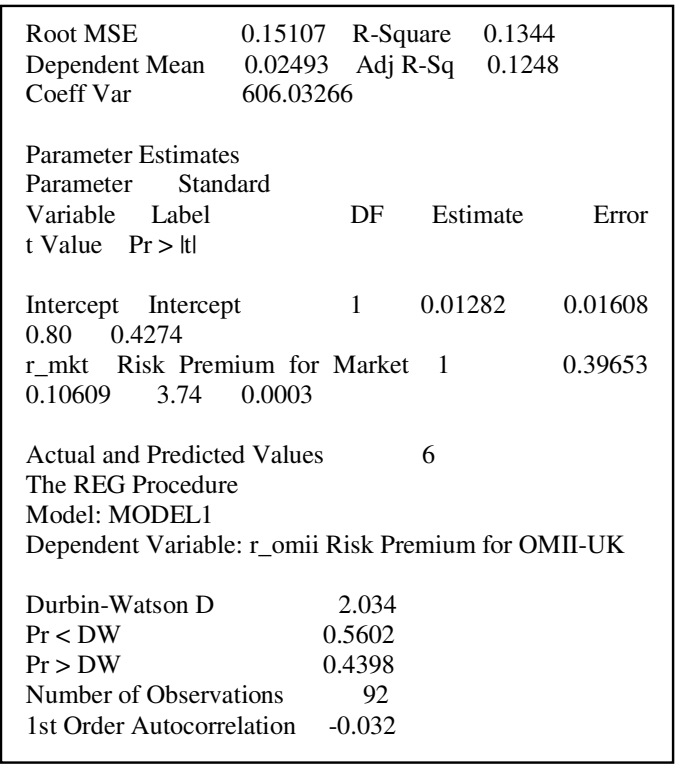

Table 2: Selected regression modelling results

Table 2 shows some selected output, which includes details and an analysis table generated from SAS computation. In summary, it shows a healthy regression. It has reached above safe zone, but does not outperform. The coding algorithm aims for the prediction for OMIIUK's Risk Premium. In other words, it predicts the organisational sustainability in short. It computes into a linear regression model. Regression is a common technique in statistics to study several variables, and to understand relationships between a dependent variable and one or more independent variables. This part of the code is to compute regression analysis.

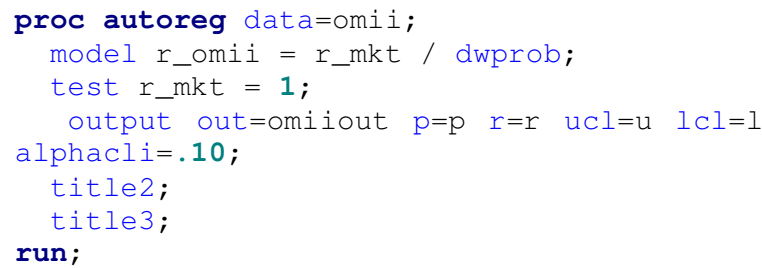

\subsection{The 3D sustainability modelling}

OMII-UK's sustainability models are presented in terms of statistical analysis earlier. Statistics still requires further analysis and interpretation, which is often presented by $2 \mathrm{D}$ graphs. Due to several factors involved, 2D models have limitations to represent business 
complexity, and often a set of 2D models are required. To simplify complexity, 3D visualisation is a preferred technique to replace a set of 2D models. Data is given into Mathematica, which computes sustainability modelling that corresponds to the OMII-UK's growth in the last three years. There are few or none of researchers getting into 3D visualisations. See Figure 7 below.

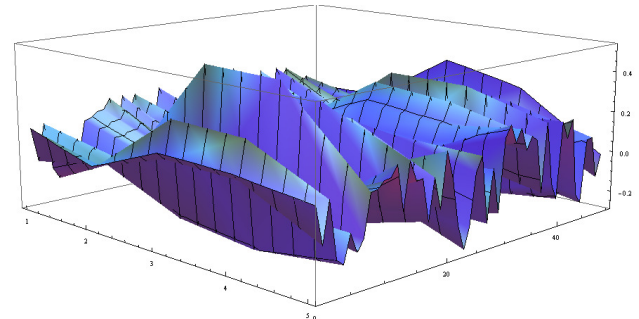

Figure 7: 3D sustainability modelling for the OMII-UK.

\subsection{Sustainability modelling in relations to the Hexagon Model}

Figure 8 refers to OMII-UK's Hexagon model back in 2007, which is well-balanced for all six elements, and also supported by peer reviews. This Hexagon model also corresponds to CAPM model, which computes a linear regression suggesting it is above safe zone but in moderate area. In relations to STAW, the occupied area is similar to a ring shape, suggesting this business model is in a defence mode in its initial phase.

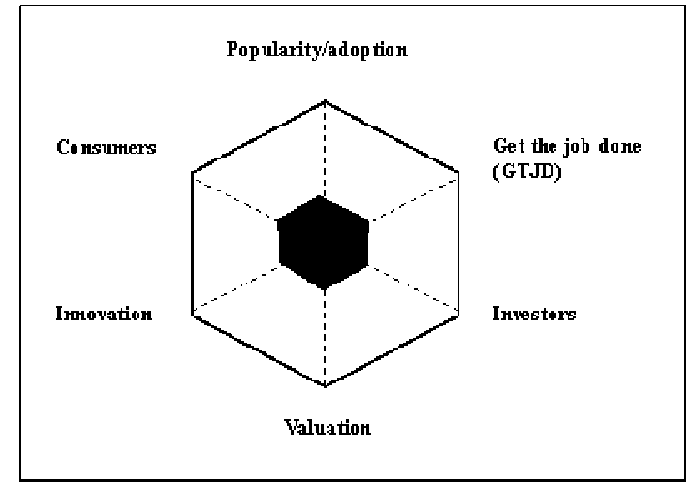

Figure 8: The Hexagon Model for the OMII-UK in 2007

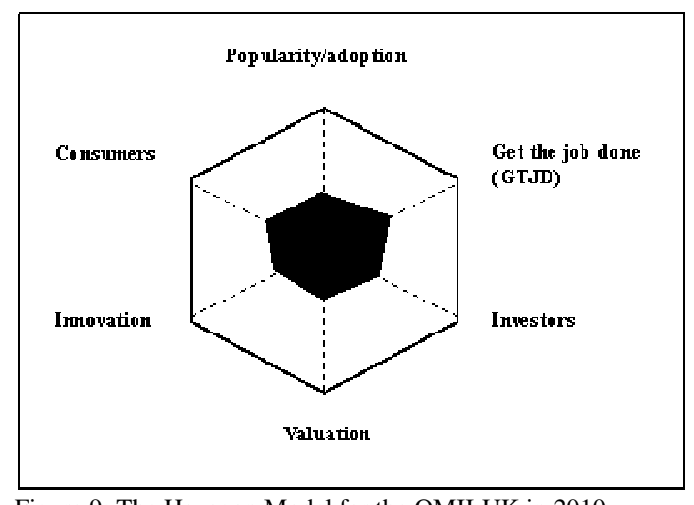

Figure 9: The Hexagon Model for the OMII-UK in 2010

In these three years of time framework, their major development is in (i) consumers, where there is a growth in numbers and users' confidence in their software; and (ii) the GTJD, where the OMII-UK has offered services tailored to users' needs and has helped users acquiring their goals. The other four elements also grow, but not as significantly as consumers and GTJD, and see Figure 9. We write $\mathrm{R}$ codes for MPT modelling, which is suitable tracking organisational growth. This can be presented in terms of risk analysis. Each of high and low risk factor is selected for modelling, and predicts estimation for OMII-UK sustainability. See Figure 10 for detail.

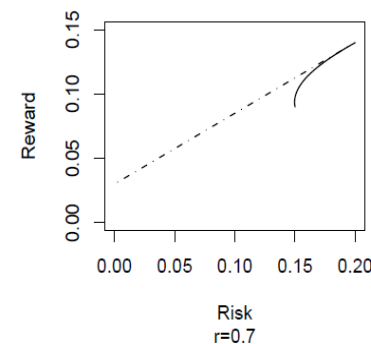

Figure 10: MPT Result by using R

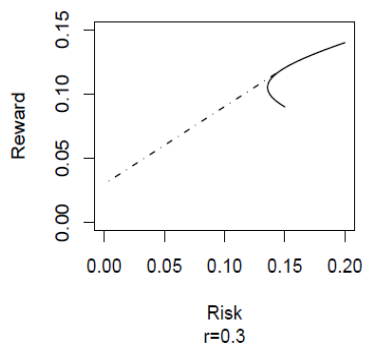

$=0.3$

\subsection{Relationship between the Cloud Cube Model (CCM) and the Hexagon Model}

The CCM is used to classify into eight business models, providing guidelines for how cloud businesses should operate and direction they strategically focus between the initial phase and next few years of business operations. The Hexagon Model is ideal to highlight strengths and weaknesses of cloud businesses at any time and also provide awareness of areas they should focus, and a quick yet effective update on sustainability by focusing on the occupied area in the Hexagon Model. The Hexagon Model bridges the gap from qualitative (CCM) to quantitative (CAPM, MPT, 3D visualisation) model, and help organisations tracking what CCM cannot quantitatively measure from. Therefore, both models complement with each other.

\subsection{Other organisations to use our approach}

An anonymous National Health Service (NHS) Trust and an anonymous University have worked together in various healthcare cloud and cloud-related projects. They have used CCM, as "Support and Contract Services" and "In-House Private Cloud" models. They also use our Hexagon Model, and their Private Cloud deployment is similar to Figure 6 on page 5. We plan to get more lessons learned and recommendation from this particular user scenario.

\subsection{In comparisons with other business models}

All business models are based on qualitative approach and these include (a) the Cloud Cube Model proposed by Jericho's Forum [14]; (b) seven models proposed by Chou [9]; (c) Cloud OSS Business Model 3.0 presented by Lawson [16]; (d) waterfall models proposed by Jeffery, Schubert and Neidecker-Lutz [13]; and (e) Linear Value Chain and Ecosystem Models proposed by Luhn and Jaekel [20]. Our models of integrated uses of 
CCM, the Hexagon model, CAPM and MPT is one of the few models that use both quantitative and qualitative approaches to provide added values.

\section{Conclusion}

Cloud computing business models are a relatively new area, and finding the right business models can enhance organisational sustainability. In this paper, we classify cloud computing business models into eight types, and discuss how the Cloud Cube Model (CCM) fits into each business model. Based on literature review and STAW, we explain rationale and elements in the Hexagon Model. Six key elements include consumers, investors, popularity, valuation, innovation and get the job done factors. Hexagon Model's key advantage allows strengths and weaknesses of cloud business models to be presented as a visual and easy-to-understand approach. Some firms' cases are presented, and similarly, case study in Private Cloud is demonstrated. By adopting the right business model, we hope organisations can stand firm in downturns and expand their businesses.

There are few quantitative approaches for sustainability, and several models are reviewed. Capital Asset Pricing Model (CAPM) is chosen, and the coding algorithm is explained. With three years of data, the linear regression corresponds to the expected result. The case study of the OMII-UK shows how sustainability can be computed. We further demonstrate sustainability with 3D visualisation enabled by Mathematica. Relations between the Hexagon model and modelling in CAPM and MPT are explained, and both aspects agree with each other. More work will be done, including vendor's lock-in, which we plan performing risk analysis and also proposal of Financial Cloud Framework. We plan to use more organisations' data including UK National Grid Service and elaborate relationship between business models, sustainability and modelling.

\section{Acknowledgement}

We thank Neil Chue Hong for his useful feedback. We thank David Fowler for proof reading.

\section{References}

[1] Anderton A, "Economics AQA" Fifth Edition, Causeway Press, 2008.

[2] Armbrust M et al., "Above the Clouds: A Berkeley View of Cloud Computing", UC Berkeley Reliable Adaptive Distributed Systems Laboratory Technical Report, February 2009.

[3] Boss G et al., "Cloud Computing", IBM white paper, Version 1.0, October 2007.

[4] Chang V et al. "Cancer Cloud Computing for Breast Cancer Research”, NHS Internal Technical Paper, July 2009.

[5] Chang V, Mills, H and Newhouse, S "From Open Source to longterm sustainability: Review of Business Models and Case studies". UK e-Science All Hands Meeting, Nottingham, UK, September 2007.
[6] Chang V, "Cloud Computing - The Integrated Personal Cloud Framework and key lessons from the Core, Healthcare and Finance", nine-month thesis technical report, School of Electronics and Computer Science, University of Southampton, March 2010.

[7] Chang V, David B, Wills G, De Roure D, "A Categorisation of Cloud Business Models", CCGrid, $10^{\text {th }}$ International Symposium on Cluster, Cloud and Grid Computing, May 2010, Melbourne, Australia.

[8] Chang V, "Financial Cloud Computing - History, Literature Review and why is it important?' University of Southampton Research Report, January 2010.

[9] Chou T, "Seven Clear Business Models", Active Book Press, 2009.

[10] Easy Strategy, http://www.easy-strategy.com

[11] Haynie M, "Enterprise cloud services: Deriving business value from Cloud Computing," Micro Focus, Technical Report, 2009.

[12] Hull J C, "Options, Futures, and Other Derivatives", Seventh Edition, Pearson, Prentice Hall, 2009.

[13] Jeffery K, Schubert H and Neidecker-Lutz B, "The Future for Cloud Computing: Opportunities for European Cloud Computing Beyond 2010”, Expert Group report, public version 1.0, January 2010.

[14] Jericho Forum, "Cloud Cube Model: Selecting Cloud Formations for Secure Collaboration Version 1.0", Jericho Forum Specification, April 2009.

[15] Joint Information System Committee (JISC), "Open Source Briefing Paper"

http://www.jisc.ac.uk/publications/publications/pub_ossbp.aspx

[16] Lawson J, "The Cloud: OSS Model 3.0", O’Reilly Conference, July 2009, San Jose, US.

http://en.oreilly.com/oscon2009/public/schedule/detail/10369

[17] Lazonick W, "Evolution of the New Economy Business Model", UMass Lowell and INSEAD, 2005.

[18] Lee S F, Roberts P et al., "Sun Tzu's The Art of War as business and management strategies for world class business excellence evaluation under QFD methodology", Business Process Management Journal, Vol. 4 No. 2, 1998, pp. 96-113. @ MCB University Press.

[19] Lohr S, "Google and I.B.M. Join in 'Cloud Computing' Research”, New York Times, October 2007

[20] Luhn A, Jaekel M, "Cloud Computing - Business Models, Value Creation Dynamics and Advantages for Customers", Simens White Paper, 2009. https://www.it-

solutions.siemens.com/b2b/it/en/global/Documents/Publications/Cloud Computing_Whitepaper_PDF_e.pdf

[21] Michaelson S W, "Sun Tzu For Execution - How to use the Art of War to Get Results", published by Adams Business, 2007.

[22] Wang L, Kunze M et al., "Cloud Computing: a Perspective Study", Grid Computing Environments Workshop (GCE’08), Austin, Texas, December 2008

[23] Waters D, "Quantitative Methods For Business" Fourth Edition, Prentice Hall, Financial Times, 2008.

[24] Wee, C H, Lee K S and Bambang, W H (1995), Sun Tzu: War and Management: Application to Strategic Management and Thinking, first printed in 1991 by Addison-Wesley.

[25] Wikipedia, Capital Asset Pricing Models (CAPM), March 2010. http://en.wikipedia.org/wiki/Capital_asset_pricing_model

[26] Wikipedia, Modern Portfolio Theory (MPT), March 2010 http://en.wikipedia.org/wiki/Modern_portfolio_theory 